\title{
PELNOMOCNICTWO DOTYCZĄCE DYSPONOWANIA FUNDUSZAMI PROPINACYJNYMI W SZADKU (1852 R.)
}

Streszczenie. Dochody z propinacji stanowiły ważną pozycje w budżecie Szadku w XIX w. Zyski z produkcji i sprzedaży alkoholu należały do mieszczan posesjonatów, którzy wybierali swych przedstawicieli w celu dysponowania dochodami. Porównanie list posesjonatów zawartych w akcie nadania pełnomocnictwa z $1852 \mathrm{r}$. oraz z $1862 \mathrm{r}$. pozwoliło na ustalenie, iż tylko $1 / 3$ tych mieszczan wystąpiła w obu wykazach. Świadczy to o dużej wymianie właścicieli nieruchomości na terenie Szadku w ciągu dekady. Większość z posesjonatów (58\%) była w 1852 r. piśmienna. Rodziny które najliczniej były wówczas reprezentowane w gronie właścicieli nieruchomości na terenie Szadku to Łazuchiewiczowie i Woszczalscy.

Słowa kluczowe: Szadek, akt notarialny, XIX w., dochody miasta, alfabetyzacja

\section{KOMENTARZ}

Zagadnienie propinacji zostało szerzej omówione w poprzednim artykule nt. pełnomocnictwa dotyczącego dysponowania funduszami propinacyjnymi w Szadku ${ }^{1}$. Niniejszy tekst omawia podobny dokument sporządzony dekadę wcześniej.

Prawo propinacji, które oznaczało monopol alkoholowy, początkowo dotyczyło warzenia piwa. Wraz z rozpowszechnieniem się produkcji i spożycia wódki w XVII-XVIII w. na ziemiach polskich obejmowało również dochody $\mathrm{z}$ gorzałki ${ }^{2}$. Dochody z propinacji odgrywały ważną rolę $\mathrm{w}$ gospodarce

* Piotr Szkutnik, dr, adiunkt, Uniwersytet Łódzki, Wydział Filozoficzno-Historyczny, Instytut Historii, Katedra Historii Historiografii i Nauk Pomocniczych Historii, 90-219 Łódź, ul. Kamińskiego 27a, e-mail: pszkutnik@poczta.onet.pl.

1 P. Szkutnik, Petnomocnictwo dotyczace dysponowania funduszami propinacyjnymi w Szadku (1862 r.), „Biuletyn Szadkowski” 2017, t. 17, s. 55-64, gdzie podano szerszą literaturę.

2 A. Zarzycka, Prawo propinacji w Królestwie Polskim w latach 1815-1830, [w:] Wielokulturowość polskiego pogranicza. Ludzie, idee, prawo. Materiaty ze Zjazdu Katedr Historycznoprawnych, Augustów 15-18 września 2002 roku, red. A. Lityński, P. Fiedorczyk, Białystok 2003, s. 431. 
polskiej ${ }^{3}$. Czynnikiem sprzyjającym rozwojowi produkcji alkoholu było jego wysokie spożycie w społeczeństwie ${ }^{4}$. W okresie staropolskim poza szlachtą jedynie miasta posiadały możliwość produkcji wódki ${ }^{5}$. W XIX w. w Królestwie Polskim na dochody miast pochodzące z propinacji składały się zyski z produkcji, sprzedaży i spożycia trunków ${ }^{6}$. Stanowiły ważną pozycję w budżetach miejskich ${ }^{7}$. Zyski z propinacji wydzierżawiano zwykle na okres trzech lat ${ }^{8}$, licząc też na przeciwdziałanie dzierżawcy nielegalnemu obrotowi alkoholami ${ }^{9}$. Według opinii Komisji Rządowej Przychodów i Skarbu z 3 lipca 1837 r. brak prawa propinacyjnego nie pozwalał na handel trunkami i uzyskiwanie w ten sposób korzyści majątkowej, ale nie odbierał możliwości wytwarzania trunków na własną potrzebę ${ }^{10}$.

W Szadku będącym miastem rządowym ${ }^{11}$, fundusz propinacyjny zwany garncowym ${ }^{12}$ należał do właścicieli nieruchomości. Były one oddawane dzierżawcy drogą licytacji. Dzierżawcą propinacji w 1840 r. był liczący wówczas 37 lat Wilhelm Kowalski zamieszkały w domu księżym zwanym Austerią ${ }^{13}$.

3 W majątkach wielkich właścicieli ziemskich od połowy XVIII w. stanowiły co najmniej połowę uzyskiwanych dochodów. Zob.: E. Kaczyńska, IV. Mieszczaństwo, [w:] Przemiany społeczne w Królestwie Polskim 1815-1864, red. W. Kula, J. Leskiewiczowa, Wrocław 1979, s. 85. W niektórych majątkach dochody z propinacji przekraczały nawet $60 \%$ ogółu dochodów z dóbr ziemskich. Zob.: K. Ślusarek, Czy dochody z propinacji, czyli produkcji wódki i piwa, uratowały galicyjskich ziemian przed bankructwem?, [w:] Polska i Polacy w XIX-XX wieku. Studia ofiarowane Profesorowi Mariuszowi Kulczykowskiemu w 70. rocznicę Jego urodzin, red. K. Ślusarek, Kraków 2002, s. 287.

4 Istniało powszechne przekonanie o leczniczych właściwościach wódki. Zob.: Z. Kuchowicz, Warunki zdrowotne wsi i miasteczek województw tęczyckiego i sieradzkiego w XVIII wieku, Łódź 1961, s. 42. Z. Kuchowicz, Spożycie alkoholu i zagadnienie jego wartości w XVIII w., [w:] Pożywienie w dawnej Polsce, red. A. Gieysztor, Warszawa 1967, s. 148-149.

5 J. Burszta, Społeczeństwo i karczma. Propinacja, karczma i sprawa alkoholizmu w społeczeństwie polskim XIX wieku, Warszawa 1951, s. 17.

6 Dochody propinacyjne wpływały np. do kasy miejskiej Kutna w XIX w. Zob.: J. Kita, Kutno w okresie zaborów (1793-1918), [w:] Kutno poprzez wieki, t. I. Do 1939 roku, red. J. Szymczak, Kutno 2011, s. 298.

7 Dochody te stanowiły podstawowe źródło utrzymania również właścicieli miast. Właściciel Zduńskiej Woli po utracie prawa propinacji w 1864 r. podpadł w kłopoty finansowe, które doprowadziły do licytacji jego dóbr. Zob.: J. Śmiałowski, Zduńska Wola. Monografia miasta do 1914 r. Łódź 1974, s. 193.

8 D. Złotkowski, Spór o dochody z propinacji w Starej Częstochowie w ostatnich latach Księstwa Warszawskiego, „Studia Historyczne” 1998, R. 41, z. 4, s. 523.

9 Nielegalnym handlem trunkami trudnili się Żydzi. Zob. np.: W. Puś, Lata zaborów (1795-1918), [w:] Łask. Dzieje miasta, red. J. Śmiałowski, Łask 1998, s. 164.

10 Archiwum Główne Akt Dawnych, Komisja Rządowa Spraw Wewnętrznych, sygn. 6706, s. 3-4.

11 W miastach prywatnych prawo propinacji było czasem przedmiotem sporu między właścicielem i mieszczanami. Zob.: M. Iwańska, Głowno w latach zaborów (1793-1918), [w:] Głowno. Dzieje miasta, red. M. Nartonowicz-Kot, Łódź 2010, s. 137-140.

12 W Tuszynie dochody te określano mianem zyskowego i ich dzierżawa rocznie przynosiła kasie miejskiej 363 ruble i 24 kopiejki dochodu w 1846 r. Zob.: Archiwum Państwowe w Łodzi (dalej: APŁ), Akta miasta Tuszyna, sygn. 151, k. 87v.

13 Karczma. 
Jego żona Bogumiła z Kwaśniewskich w wieku 28 lat 9 czerwca 1840 r. urodziła na Bobowni Księżej córkę Antoninę. Świadkami wymienionymi w akcie byli obywatel Szadku Wojciech Lipiński liczący 40 lat i szwajcar kościelny Jakub Jaworski liczący 41 lat, obaj zamieszkali w Szadku. Chrzestnymi dziecka zostali Feliks Woszczalski i Florentyna Olszewska ${ }^{14}$.

Wspomniani Wojciech Lipiński jak i Feliks Woszczalski, byli właścicielami nieruchomości w Szadku, którzy wraz z kilkudziesięcioma posesorami 12 lat później 29 lutego 1852 r. wybrali pełnomocników funduszu propinacyjnego w Szadku ${ }^{15}$. Przedstawiciele ci wraz z magistratem mieli dysponować dochodami $\mathrm{z}$ trunków na potrzeby miasta w tym opłacania podatków. Spośród uprawnionych wówczas do wyboru $69^{16}$ mieszczan-właścicieli (w 1862 r. było ich 68), większość, tj. 40, była piśmienna (10 lat później było ich 50 czyli o 10 więcej). Piśmienni stanowili zatem 58\% wymienionych właścicieli posesji. Poza polskimi nazwiskami pojawia się kilka (4) niemiecko brzmiących, być może ewangelików.

Spośród wymienionych w 1852 r. właścicieli posesji tylko 23 (na 69) znalazło się również wśród decydujących o wyborze pełnomocników 10 lat później w $1862 \mathrm{r}$. W ciągu dekady, aż 2/3 właścicieli uległo zatem wymianie ${ }^{17}$.

Spośród właścicieli nieruchomości w 1852 r. siedem rodzin (Lipscy, Lipińscy, Niedźwieccy, Osękowscy, Rudeccy, Uznańscy, Wrońscy) posiadało po dwóch przedstawicieli w tym gronie, trzech posiadali Łazuchiewiczowie oraz aż czterech Woszczalscy.

Podobnie w 1862 r. było siedem rodzin (Garczyńscy, Kraiewscy, Kraszewscy, Lipscy, Sadowscy, Wrońscy, Wróblewscy), których reprezentowały w gronie właścicieli po dwie osoby. Trzy rodziny (Kobusiewiczowie, Łazuchiewiczowie, Woszczalscy) reprezentowało po trzech przedstawicieli oraz jedna (Adamkiewiczowie) przez czterech. Najliczniejszą reprezentację w gronie właścicieli i posiadaczy praw propinacyjnych utrzymali w analizowanej dekadzie Łazuchiewiczowie i Woszczalscy.

14 APŁ, Urząd Stanu Cywilnego Szadek, sygn. 77, Akta urodzonych, nr 137 z 1840 r.

15 APŁ oddział w Sieradzu, Akta notariusza C. Stokowskiego w Szadku, sygn. 6, nr 71, k. $130-131$.

$16 \mathrm{~W}$ wykazie zapewne w wyniku pomyłki widnieją dwie pozycje z numerem 47.

17 Wykaz właścicieli nieruchomości w Szadku, którzy występują na numerowanych listach posesorów w 1852 (pierwszy numer) i w 1862 r. (drugi numer): 1/23 Jakub Klarzyński, 4/17 Marcin Wroński, 7/28 Feliks Woszczalski, 9/11 Stanisław Sarnikowski, 11/3 Jan Lipski, 16/44 Leon Lipiński, 29/43 Marcin Zalewski, 30/38 Jan Osękowski, 33/33 Karol Paykr, 36/1 Teofil Szwepski, 40/48 Marcin Szymanowicz, 42/15 Paweł Sadowski, 43/49 Marcin Sowiński, 46/54 Jakub Czekalski, 53/2 Kacper Garczyński, 54/7 Tomasz Uznański, 56/18 Walerian Zegarowski, 57/9 Ludwik Cypryński, 63/19 Kazimierz Kurowski, 64/47 Antoni Nawrocki, 65/20 Michał Uznański, 66/63 Michał Wiśniewski, 67/50 Antoni Kluszczyński. Spośród ww. tylko Karol Paykr posiadał tą samą pozycję w obu wykazach, co było zapewne dziełem przypadku. 
W wykazie z 1852 r. widnieje 25 nazwisk $^{18}$, których w wykazie z 1862 r. już nie podano, ale w to miejsce pojawiło się tam wówczas 21 nowych ${ }^{19}$. Świadczy to o sporym obrocie nieruchomości w mieście i częstych zmianach właścicieli w wyniku kontraktów lub dziedziczenia.

\section{NOTA EDYTORSKA}

Modernizacji pisowni dokonano zgodnie ze wskazówkami instrukcji wydawniczej $^{20}$. Niektóre zdania podzielono, wprowadzono kropki w miejsce myślników oraz przecinki. W nawiasie kwadratowym [s] skróconym sic oznaczono zbędne lub błędnie zapisane wyrazy. W nawias kwadratowy ujęto odczyt niepewny oraz zaznaczono początek danej strony w akcie. Zgodnie z obecnymi regułami zastosowano duże litery. Liczbami zastąpiono liczebniki. Wprowadzono akapity.

Litery i, j, y oddano zgodnie ze współczesnymi zasadami: Andrzey - Andrzej, Błażey - Błażej, Felicyan - Felicjan, Lucyan - Lucjan, Maciey - Maciej, następującey - następującej, posiadaiącemi - posiadającemi, podpisuią - podpisują, propinacyinego - propinacyjnego, przyiąć - przyjąć, reyentem - rejentem, stawaiący - stawający, tuteyszego - tutejszego, Waleryan - Walerian, warszawskiey - warszawskiej, Woyciech - Wojciech, wybieraią - wybierają, zeznaiący - zeznający, zmierzaiących - zamierzających. Podobnie literę x: Alexandra-Aleksandra, Felix - Feliks, Maxmilianem - Maksymilianem. Wyraz przedemną zapisano oddzielnie. Podwojone litery zastąpiono pojedynczymi: interessie - interesie, kancellaryi - kancelarii. Pozostawiono oryginalne brzmienie wyrazów: Krysztof, posiadającemi, powyż, zamieszkałemi.

\section{PEŁNOMOCNICWO MIESZCZAN SZADKOWSKICH Z 1852 ROKU DOTYCZĄCE DYSPONOWANIA FUNDUSZAMI PROPINACYJNYMI}

Or.: Archiwum Państwowe w Łodzi oddział w Sieradzu, Akta notariusza C. Stokowskiego w Szadku, sygn. 6, nr 71, k. 130-131.

18 Berlikowski, Borkowski, Czarnecki, Dobersztein, Gamalski, Gruszka, Karsznicki, Korzenny, Kruszewski, Mükke, Nadolski, Nagalski, Niedzwiecki, Nowicki, Olszewski, Orłowski, Popławski, Rozmarynowski, Rudecki, Seplewicz, Skaliński, Sznur, Uziembło, Wieczerkiewicz, Żelisławski.

19 Adamkiewicz, Adamowicz, Dąbrowski, Dziamarski, Gibetner, Jankowski, Kamiński, Kobusiewicz, Kraiewski, Kraszewski, Krauze, Kulamowicz, Kupciński, Maliszewski, Rudnicki, Stamirowski, Szeplewicz, Śmiałowski, Trynkaus, Tyll, Zabłocki.

${ }_{20}$ Instrukcja wydawnicza dla źródet historycznych od XVI do połowy XIX wieku, red. K. Lepszy, Zakład im. Ossolińskich, Wrocław 1953; J. Tandecki, K. Kopiński, Edytorstwo źródet historycznych, Instytut Historii PAN, Warszawa 2014, s. 173-178. Odpowiednich odsyłaczy przypisów tekstowych i rzeczowych nie zastosowano z powodów technicznych. 
[k. 130] Działo się w mieście okręgowym Szadku w powiecie sieradzkim, guberni warszawskiej w kancelarii rejenta dnia 17/29 lutego roku $1852^{21}$.

Przede mna Celestynem Stokowskim rejentem kancelarii okręgu szadkowskiego w mieście okręgowym Szadku w powiecie sieradzkim guberni warszawskiej zamieszkałym w obecności świadków w końcu aktu tego wymienionych stawili się osobiście:

1. Jakub Klarzyński 22, 2. Fabian Uziembło, 3. Lucjan Borkowski ${ }^{23}$, 4. Marcin Wroński, 5. Mikołaj Seplewicz, 6. Jakub Korzenny, 7. Feliks Woszczalski24, 8. Jan Nowicki, 9. Stanisław Sarnikowski, 10. Tomasz Żelistawski, 11. Jan Lipski, 12. Józef Kruszewski, 13. Wojciech Nagalski, 14. Bogumit Orłowski, 15. Krysztof Dobersztein, 16. Leon Lipiński, 17. Wojciech Lipinski, 18. Felicjan Gruszka, 19. Pawet Skaliński, 20. Pawet Łazuchowicz, 21. Jan Gamalski, 22. Wróblewski Tomasz, 23. Paweł Łazuchiewicz drugi, 24. Wawrzyniec Woszczalski, 25. Błażej Berlikowski, 26. Kacper Wroński, 27. Leon Wieczerkiewicz, 28. Mikołaj Rozmarynowski, 29. Marcin Zalewski, 30. Jan Osękowski, 31. Marcin Budziński, 32. Kacper Popławski, 33. Karol Paykr, 34. Karol Mükke, 35. Jan Czarnecki, 36. Teofil Szwepski, 37. Stanisław Woszczalski, 38. Pawet Niedzwiecki, 39. Ignacy Niedzwiecki, 40. Marcin Szymanowicz, 41. Wawrzyniec Olszewski, 42. Pawet Sadowski, 43. Marcin Sowiński, 44. Józef Rudecki, 45. Felicjan Lipski, 46. Jakub Czekalski, 47. Felicjan Woszczalski, 47. Andrzej Łazuchiewicz, 48. Tomasz Nadolski, 49. Marcin Sznur, 50. Stanistaw Karsznicki, 51. Nikodem Woszczalski, 52. Dominik Kozłowski 25, 53. Kacper Garczyński, 54. Tomasz Uznański, 55. Maciej Osękowski, 56. Walerian Zegarowski, 57. Ludwik Cypryński, 58. Jan Woldanowski, 59. Kacper Rudecki, 60. Maci[e]j Rudecki, 61. Stanisław Uznański, 62. Jan Pakowski Młody, 63. Kazimierz Kurowski, 64. Antoni Nawrocki, 65. Michat Uznański, 66. Michat Wiśniewski, 67. Antoni Kluszczyński, 68. Ferdynand Hayman ${ }^{26}$.

Wszyscy stawający jako obywatele miasta tutejszego Szadku wspótwłaściciele, w mieście Szadku w powiecie sieradzkim guberni warszawskiej [...] zamieszkali i zamieszkanie prawne do wykonania aktu tego dla siebie przybierajacy, mnie rejentowi z osób swych znani, czynić urzędownie [k. 130v] prawomocni ${ }^{27}$, jawnie, dobrowolnie

${ }^{21}$ W lewym górnym rogu aktu adnotacja: „Pierwszy i drugi wyciąg na stęplach po kopiejek siedm i pół szacunkowych wydane plenipotentom na ręce Jakuba Klarzyńskiego dnia /1/ 13 marca roku 1852. Stokowski”. Po środku stempel opłaty skarbowej wartości 7 i pół kopiejki.

${ }^{22}$ Zob.: P. Szkutnik, Legaty na rzecz bractw kościelnych w Szadku w latach 50-tych XIX w., „Biuletyn Szadkowski” 2016, t. 16, s. 67.

${ }^{23}$ Zob.: P. Szkutnik, Julian Godziński (1840-1913) życiorys wójta Szadku, „Biuletyn Szadkowski” 2003, t. 3, s. 44.

24 Zob.: P. Szkutnik, Legaty..., s. 70.

${ }_{25}$ Zob.: P. Szkutnik, Legaty..., 2016, s. 67, 70, 73; B. Czyżewski, Nagrobki przy kościele Wniebowzięcia NMP i św. Jakuba Apostoła w Szadku, „Biuletyn Szadkowski” 2016, t. 16, s. 52.

26 Nazwiska numerowane od pozycji 55 do pozycji 68 dopisano na marginesie aktu. Poniżej zamieszczono inicjały: P.N. J.N. J.B. L.B. J.G. M S T. Sz. T. [Zi]. [Jejn]. Krzy. T U M.S. J.S. Stokowski.

27 Wyraz przeniesiony z poprzedniej strony, gdzie częściowo zastał zapisany jako „prawo”. 
zeznali i niniejszym zeznają akt petnomocnictwa szczególnego w osnowie następujacej. Iż będąc wtaścicielami funduszu propinacyjnego w mieście Szadku istniejącego, czyli garcowego przeto do dysponowania tym funduszem wraz z magistratem na potrzeby miasta, oplacanie podatków i innych wydatków, do robienia obrachunków z czasu zeszłego $i$ w czasie przyszłym, zgoła do zarzadzania tym funduszem jedynie na korzyść miasta stosownie do rozporządzenia władzy wyższej wybierają oraz do wszelkich działań ku dobru miasta zmierzających wybieraja [s] za szczególnych petnomocników Fabiana Uziembło pisarza sądu pokoju $i$ wspótwłaściciela, Aleksandra Zalewskiego obrońcę sadu tutejszego i wspótwłaściciela, Konstantego Szyligowskiego doktora, Macieja [U]dmińskiego i Jakuba Klarzyńskiego obywateli w mieście tutejszym Szadku zamieszkałych. Dając im zupetna moc w imieniu swoim czyli miasta działaniu $w$ powyż opisanym interesie wraz z magistratem, a co ciz wybrani powyz petnomocnicy w interesie tym zdziataja i postanowia tu zeznajacy za ważne, siebie obowiazujace tak jakby to sami uczynili przyjać i wykonać obowiazuja się. Moca tego dobrowolnego zeznania, które stawający po odczytaniu, zrozumieniu i przyjęciu wraz z świadkami prawne przymioty posiadajacemi w mieście Szadku okręgu szadkowskim zamieszkałemi Maksymilianem Biernackim obrońca sadowym i Antonim Serafinowiczem aplikantem sadowym ze mna rejentem podpisuja.

Fabian Uzięmbło, Marcieni [s] Wroński, Jan Bakowski [s], Feician [s] Lipski, Józef Kraszewski, Felix Wozszczalskj [s], Jan Stowicki, Kristolf [s] Doberstein, Marcin Szymanowicz, Mikołay Seplewicz, Marcin Sowinski, Jan Gamalski, Tomasz Zelisławski, Lucian Borkowski (fot. 1), [k. 131] Karol Miücke, Pawet Sadowski, Wawrzyniec Olszewski, Józef Rudecki, Jakub Korzenny, Woyciech Nogalski, Pawet Niedzwiecki, Ignacy Niedzwiecki, Felicyan Woszczalski, Wawrzyniec Rudecki, Paweł Łazuchiewicz, Stanisław Woszczalski, Paweł Łazuchiewicz, Jan Czarnecki, Teofiel Szwepsky, Tomasz Uznanski, Nikodem Wosczalski, Waleryan Zegarowski, Maci Osękowski, Leon Lipiński, Jan Pakowski, Dominik Kozłowski, Antoni Nawrocki, Michat Wisniewski, Ferdynand Heymann, Jan Kobusiewicz, Jan Śmiałowski (fot. 2).

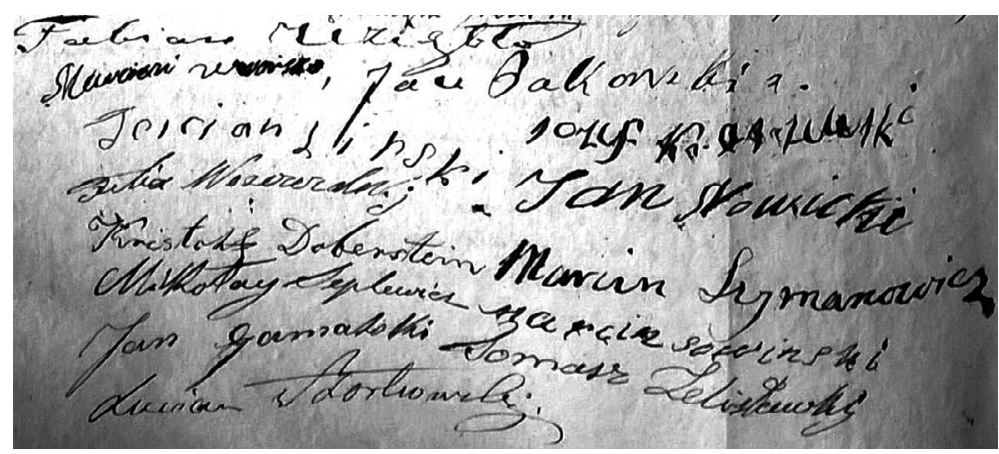

Fot. 1. Podpisy pod aktem pełnomocnictwa

Źródło: APŁ oddział w Sieradzu, Akta notariusza C. Stokowskiego w Szadku, sygn. 6, nr 71, k. 130v. 


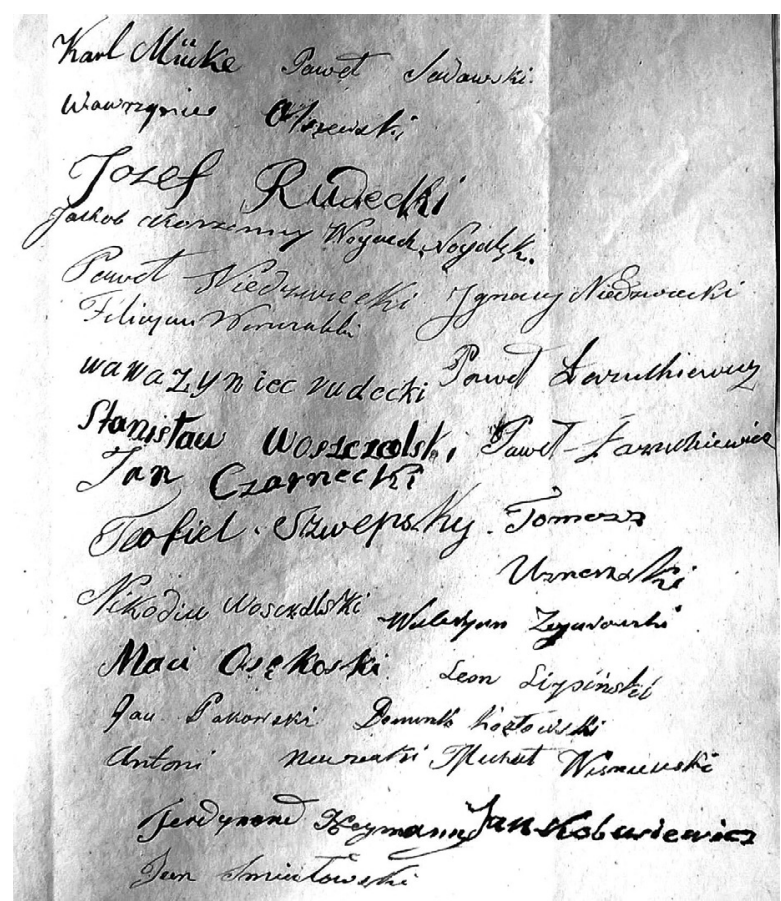

Fot. 2. Podpisy pod aktem pełnomocnictwa (c.d.)

Źródło: APŁ oddział w Sieradzu, Akta notariusza C. Stokowskiego w Szadku, sygn. 6, nr 71, k. 131.

Reszta komparentów oświadczyła, że pisać nie umie i stempel szacunkowy do aktu tego za kopiejek trzydzieści składają.

Maksymilian Biernacki świadek, Antoni Serafinowicz świadek, Celestyn Stokowski rejent.

\section{Bibliografia}

Archiwum Główne Akt Dawnych, Komisja Rządowa Spraw Wewnętrznych, sygn. 6706. Archiwum Państwowe w Łodzi, Akta miasta Tuszyna, sygn. 151, k. 87v.

Archiwum Państwowe w Łodzi oddział w Sieradzu, Akta notariusza C. Stokowskiego w Szadku, sygn. 6.

Archiwum Państwowe w Łodzi, Urząd Stanu Cywilnego Szadek, sygn. 77.

Burszta J., Społeczeństwo i karczma. Propinacja, karczma i sprawa alkoholizmu w spoteczeństwie polskim XIX wieku, Warszawa 1951.

Czyżewski B., Nagrobki przy kościele Wniebowzięcia NMP i św. Jakuba Apostoła w Szadku, „Biuletyn Szadkowski” 2016, t. 16. 
Instrukcja wydawnicza dla źródet historycznych od XVI do połowy XIX wieku, red. K. Lepszy, Zakład im. Ossolińskich, Wrocław 1953.

Iwańska M., Głowno w latach zaborów (1793-1918), [w:] Glowno. Dzieje miasta, red. M. Nartonowicz-Kot, Łódź 2010.

Kaczyńska E., IV. Mieszczaństwo, [w:] Przemiany spoleczne w Królestwie Polskim 1815-1864, red. W. Kula i J. Leskiewiczowa, Wrocław 1979.

Kita J., Kutno w okresie zaborów (1793-1918), [w:] Kutno poprzez wieki, t. I. Do 1939 roku, red. J. Szymczak, Kutno 2011.

Kuchowicz Z., Spożycie alkoholu i zagadnienie jego wartości w XVIII w., [w:] Pożywienie w dawnej Polsce, red. A. Gieysztor, Warszawa 1967.

Kuchowicz Z., Warunki zdrowotne wsi i miasteczek województw tęczyckiego i sieradzkiego w XVIII wieku, Łódź 1961.

Puś W., Lata zaborów (1795-1918), [w:] Lask. Dzieje miasta, red. J. Śmiałowski, Łask 1998.

Szkutnik P., Julian Godziński (1840-1913) życiorys wójta Szadku, „Biuletyn Szadkowski" 2003, t. 3.

Szkutnik P., Legaty na rzecz bractw kościelnych w Szadku w latach 50-tych XIX w., „Biuletyn Szadkowski" 2016, t. 16.

Szkutnik P., Petnomocnictwo dotyczace dysponowania funduszami propinacyjnymi w Szadku (1862 r.), „Biuletyn Szadkowski” 2017, t. 17.

Ślusarek K., Czy dochody z propinacji, czyli produkcji wódki i piwa, uratowaty galicyjskich ziemian przed bankructwem?, [w:] Polska i Polacy w XIX-XX wieku. Studia ofiarowane Profesorowi Mariuszowi Kulczykowskiemu w 70. rocznicę Jego urodzin, red. K. Ślusarek, Kraków 2002.

Śmiałowski J., Zduńska Wola. Monografia miasta do 1914 r., Łódź 1974.

Tandecki J., Kopiński K., Edytorstwo źródet historycznych, Instytut Historii PAN, Warszawa 2014.

Zarzycka A., Prawo propinacji w Królestwie Polskim w latach 1815-1830, [w:] Wielokulturowość polskiego pogranicza. Ludzie, idee, prawo. Materiały ze Zjazdu Katedr Historycznoprawnych, Augustów 15-18 września 2002 roku, red. A. Lityński i P. Fiedorczyk, Białystok 2003.

Złotkowski D., Spór o dochody z propinacji w Starej Częstochowie w ostatnich latach Księstwa Warszawskiego, „Studia Historyczne”, R. 41, 1998, z. 4.

[Artykuł wpłynął: kwiecień 2018; akceptacja: sierpień 2018] 


\title{
LETTERS OF ATTORNEY CONCERNING REVENUES FROM TAPROOM PRIVILEGE IN SZADEK (1852)
}

\begin{abstract}
Summary
Revenues from taproom constituted a major item in the budget of Szadek in XIX century. Profit from producing and selling liquor belonged to real estate owners, who chose their proxies to administer the income. Comparison of lists of estate owners contained in letters of attorney from 1852 and 1862 made it possible to establish that only $1 / 3$ of those burghers appeared in both lists. This indicates that during a decade there was considerable exchange of property owners in Szadek. The majority of them (58\%) were literate. The families which whose members were most numerous in the group of estate owners in Szadek are Łazuchiewicz and Woszczalski.
\end{abstract}

Keywords: Szadek, notarial deed, XIX century, city revenues, literacy 